\title{
Using ICT as the Tools of Forming the Senior Pupils' Research Competencies in the Profile Chemistry Learning of Elective Course "Basics of Quantitative Chemical Analysis"
}

\author{
Pavlo P. Nechypurenko ${ }^{[0000-0001-5397-6523]}$ and \\ Vladimir N. Soloviev ${ }^{[0000-0002-4945-202 \mathrm{X}]}$ \\ Kryvyi Rih State Pedagogical University, \\ 54, Gagarina Ave., Kryvyi Rih, 50086, Ukraine \\ \{acinonyxleo, vnsoloviev2016\}@gmail.com
}

\begin{abstract}
Aims of the study: to substantiate possibilities of the research competencies formation among senior pupils in terms of profile Chemistry learning by means of practical using information and communication technology while accomplishing an elective course "Basics of quantitative chemical analysis". This research considers the influence of various ICT tools on the formation of individual study and research competencies, in particular the system components of the research competencies among senior pupils in terms of profile Chemistry learning and the methods of their practical applying while accomplishing an elective course "Basics of quantitative chemical analysis". Object of the study: ICT tools for Chemistry learning. Subject of the study: ICT tools of research competencies formation among senior pupils in terms of profile Chemistry learning. Methods of the study: reviewing and analyzing scientific publications, expert evaluation, summarizing pedagogical experience. Results of the study: the system of research competencies formation among senior pupils is effectively provided by the correct selection of ICT tools and conditions of their applying for the certain research competence formation, which embodies system components. Our research confirms the idea that the most ICT tools are to be leading in the development of research competencies among senior pupils in profile Chemistry learning. They are successfully tested by means of their applying in the process of studying the elective course "Basics of Quantitative Chemical Analysis". They show the high effectiveness. Our study confirms that virtual chemical laboratories are the most universal and influential tools of forming the research competencies among senior pupils in profile Chemistry learning.
\end{abstract}

Keywords: ICT, profile Chemistry learning, senior pupils' research competencies, methods of using ICT as a tool of forming the senior pupils' research competencies in terms of profile Chemistry learning, computer-oriented elective course "Basics of quantitative chemical analysis".

\section{Introduction}

While solving the scientific problem of using the ICT as tools of forming the senior pupils' research competencies in terms of profile Chemistry 
learning, the following main results were obtained in past works: performing the theoretical analysis of research competencies formation among senior pupils' in terms of profile Chemistry learning [4, 5, 13]; creating the system of research competencies among senior pupils' in profile Chemistry learning [11]; defying the ICT tools for profile Chemistry learning, which will contribute to the development of pupils' research competencies (the electronic spreadsheets, the tools of educational achievements control and self-control, the tools for creating multimedia presentations, the general-purpose search systems, the learning management systems, the text editors, the cloud-oriented tools of supporting joint research and study activities, the adaptive automated Chemistry training systems, the virtual chemical laboratories, the electronic periodic systems, the tools for computer modeling of chemical processes, the Chemistry educational games, the popular science and vocational chemical information Internet resources, the Chemistry program and method complexes, the simulators and electronic workshops, the Chemistry search systems, the chemical editors) $[6,8,9,12,14]$; developing the ICT model of research competencies formation among senior pupils' in profile Chemistry learning and its theoretical justification [5]; developing the method components of using ICT as the tools of forming research competencies among senior pupils' in profile Chemistry learning and experimental testifying of its effectiveness $[7,10,15]$.

The system of senior pupils' research competencies in profile Chemistry learning [11] includes three groups:

1. General science competencies are related to the mastery of universal research methods. They are necessary for the research activity in any scientific discipline (GRC-01 - the ability to formulate the research hypothesis; GRC-02 - the ability to plan the hypothesis testing; GRC-03 - the ability to realize and justify the relevance of the research; GRC-04 - the ability to evaluate the moral and social aspects of scientific research; GRC-05 - the ability to find and use the reference materials that are necessary for the research; GRC-06 the ability to think critically, GRC- 07 - the ability to analyze and formalize the research results; GRC-08 - the ability to formulate conclusions; GRC-09 - the ability to substantiate the submission of research results; to protect the own opinion; to discuss; GRC-10 the ability to work together in the research process);

2. Natural science competencies are related to the research of the real natural objects and their interconnections. They are necessary for the research activities in the field of Natural Sciences (SRC-01 - 
the formation of representations about the stages of the cognitive activity in Natural Sciences, the Elements of Metrology; SRC-02 the ability to plan an experiment; SRC- 03 - the ability to carry out the individual operations competently during the experiment; SRC-04 - the ability to conduct experiments in order to know the properties of bodies and substances, to identify the features of the growth, the development and the behavior of organisms; SRC05 - the ability to adhere to the safety rules during the experiment; SRC-06 - the ability to perform the mathematical analysis of the experimental research results; $\mathrm{SRC}-07$ - forming the representations of the general laws of nature and the natural sciences picture of the world, the general structure of the universe, the integrity of nature; SRC-08 - the ability to use the experimental and statistical methods and modeling the objects of live and inanimate nature; SRC-09the ability to distribute work in the process of experiment that the purpose of optimization);

3. Chemical competencies, which are related to the mastery of special chemical research methods and necessary for the research activities in different branches of Chemistry (CRC-01 - the ability to distinguish the chemical phenomena of nature from the others; CRC- $02-$ the ability to use chemical dishes and equipment correctly; CRC-03 - the ability to adapt the existing chemical dishes and equipment for the experiment needs; CRC- 04 - the ability to compose and use devices for carrying out the experiments; CRC-05 - the ability to perform the laboratory operations correctly: heating, cooling, filtering, mixing, weighing, etc.; CRC-06 - the ability to use chemical symbols, formuli, modern Ukrainian chemical nomenclature; CRC-07 - the ability to predict the course of chemical reactions, based on the properties of the substances that are taking part in them, and the conditions of the reaction; CRC-08 - the ability to justify the relationship between the structure of matter and its properties; CRC-09 - the ability to perform the various types of chemical calculations; CRC-10 - the ability to draw conclusions about the properties of matter, based on the structure of the molecule substances; CRC-11 - the ability to draw conclusions about the structure of substances based on their properties; CRC-12 - the ability to solve the experimental problems in chemistry. 


\section{The Aim of the Study}

Therefore, the aim of the study is to substantiate possibilities of ICT implementing in the elective course "Basics of Quantitative Chemical Analysis" in order to form research competencies among senior pupils while profile Chemistry learning, as well as to develop the individual method components of using ICT as tools of forming research competencies among the senior pupils' while their profile Chemistry learning.

\section{Methods of using ICT as tools of forming the senior pupils' research competencies in the elective course "Basics of Quantitative Chemical Analysis"}

Let us consider how the selected ICT tools used in the elective course "Basics of Quantitative Chemistry Analysis" form the research competencies among senior pupils while profile Chemistry learning.

Electronic spreadsheets are used within the elective course "Basics of Quantitative Chemistry Analysis" as one of the most convenient ICT tools for support and automation of study and research activities. They are used primarily for the filling, saving, recording and processing numerical or other data obtained during the experiment, or necessary for task solving. In this case electronic spreadsheets represent a symbiosis of the laboratory journal, which is the tool of data processing and its visual representation. According to the results of expert evaluation [8], the total contribution of electronic spreadsheets in the formation of research competencies system among senior pupils while profile Chemistry learning is about $6.64 \%$.

Electronic spreadsheets are the leading ICT tools in formation of SRC-06, GRC-07, SRC-08 and CRC-09. According to expert evaluation electronic spreadsheets are the only effective tools of forming SRC-06.

The tools of educational achievements control and self-control are not a leading tools for any of research competencies. However their overall contribution to the formation of the research competencies system among senior pupils while profile Chemistry learning is quite significant and is about $5.63 \%$. It using can considerably impact the formation of GRC-06 and CRC-09. It can be seen during precise controlling and self-controlling the personal Chemistry knowledge and skill level pupils have to make certain calculations and apply critical thinking, to obtain or select correct answers to the tasks.

Due to these ICTs in most cases precise and final control and self-control are used to evaluate pupils' educational achievements in Basics Quantitative 
Chemical Analysis both in local (using the MyTest program) and remote (built into the Moodle system at http://ict-chem.ccjournals.eu test editors) mode.

Taking into account the peculiarities of the elective course "Basics Quantitative Chemical Analysis" applying tests with close-ended format tasks provides an opportunity to check the facts knowledge: the names of reagents, equipment, rules for individual chemical analysis operations related to $\mathrm{CRC}-06$. Open-ended format tasks provide an opportunity to check the knowledge of the main terms, formuli and laws used in Quantitative Chemical Analysis, skills to solve the simplest calculation problems associated with CRC-09. Match-finding tasks can be used both to check the knowledge of actual material and understanding the certain laws, rules, GRC-06 and GRC-08. The tasks on establishing the correct sequence allow to check the knowledge and understanding the algorithms of chemical analytical studies, CRC-05, SRC-02, etc.

The main focus is put on the test tasks, which are based on the calculation problems. During studying the abovementioned elective course, senior pupils learn to solve several types of problems. Among them are the following: the calculation of analysis results, the magnitude of errors, the preparation of reagent solutions, the result validity etc. (research competencies GRC-07, SRC-06, CRC-09). Similar calculation problems can be transformed into open or close-ended format tasks.

The tests checking pupils' knowledge contain simple one-step calculation problems, which allow us checking the formation of these research competencies. Controlling the ability to solve complicated two or more step calculation problems in Chemistry and carrying out individual control works with further result analyzing are reasonable.

To solve the tasks of the first complexity level, the pupil has to recognize or identify certain objects or phenomena associated with the formation of the CRC-01. The most appropriate test tasks for this complexity level are close-ended format tasks, which provide one or multioption correct variant answers and the tasks of correspondence finding.

To solve tasks of the second complexity level, it is necessary to perform such operations as non-clue recollecting, solving typical tasks that include the usage of previously studied algorithms, formuli, rules, etc. We considered open-ended format tasks the most convenient ones for this complexity level. Among them are the tasks of establishing the correct sequence and appropriately built-up tasks for establishing conformity and close-ended format tasks (mostly represented by the calculation problems).

The tasks of the third complexity level include pupil heuristic activity, 
the ability to use critical thinking in problem solving (GRC-06) such as: the strategy of actions in non-standard situations, solving tasks, which do not explicitly contain all necessary data. For this level, the most sufficient tasks are open-ended format tasks, such as the tasks of establishing the correct sequence and correspondence finding.

The fourth complexity level includes the problem solving ability and creative tasks, which do not presuppose a prior plan of solving or do not correspond to the usual problem-solving strategies. Setting the tasks of this type and their implementation requires the formation of all research competencies components at a high level.

The tools for creating multimedia presentations are leading for the formation of GRC-07, GRC-08 and GRC-09. As for the GRC-09 the tools of developing multi-media presentations are the only leading ones. The total contribution of these tools to the formation of research competencies system among senior pupils in profile Chemistry learning is $12.76 \%$.

The tools for creating multimedia presentations are used by pupils at the final stages of study and research especially for completing results of project implementation, presenting reports and individual works etc. The process of creating a presentation meeting all the content and structure requirements, demands from pupils to show skills of highlighting the key points; presenting the report content clearly, plainly and briefly; making conclusions; creating and executing visual aids (figures, diagrams, schemes); thinking over the report script etc.

General-purpose search systems are the main and simultaneously the only one ICT tools used for such research competences formation as GRC05. However the total contribution of general-purpose search systems into the formation of research competencies system among senior pupils in profile Chemistry learning is quite significant $-9.39 \%$.

Applying general-purpose search system is possible and valid at all stages of the education process within the elective course "Basics of Quantitative Chemical Analysis". The objective of using general purpose search systems is not only to provide pupils with the required data amount for more detailed and profound mastering the elective course materials, but also to develop their skills in formulating search queries, critical quality assessment of link sources, which are offered by the search system.

Learning management systems (LMS) are the leading tools of GRC-10 formation. The total contribution of these tools to the formation of research competencies among senior pupils in profile Chemistry learning is $7.66 \%$.

We use the Moodle LMS (access mode: http://ict-chem.ccjournals.eu), which hosts the digital version of the elective course "Basics of Quantitative 
Chemical Analysis". Using the Moodle LMS provides the opportunity to arrange, place and organize teaching materials. It also supports distance course studying and organizes joint work between teachers and pupils as well as pupils with each other, contributing to the formation of GRC-10 and SRC-09. The LMS serves as a special kind of organizing teaching materials and other ICT tools necessary to master the course and collaborate with users.

Text editors are the leading tools of GRC-07 and GRC-08 formation, while the total contribution of text editors to the development of research competencies system is $7.26 \%$.

Taking into account that text creating, editing and formatting is an integral part of the pupil's study and research activities and their communication by ICT tools. Text editors have been used in all stages of the elective course "Basics of Quantitative Chemical Analysis". The particular importance of text editors acquires while making reports about the results of the research work. Consequently this tools is considered to be the leading one in the formation of general research competencies and contributes to the formation of GRC-10. The significant contribution of text editors to the formation of $\mathrm{CRC}-06$ should be noted, since this research competence is also related to the need to formulate and format the texts properly.

The cloud-oriented tools of supporting joint research and study activities are specific ICT tools for research competencies formation among senior pupils in profile Chemistry learning. These tools are leading in forming the only one research competence and thus they have the lowest indicators of total contribution to the formation of the research competencies system among senior pupils in profile Chemistry learning - 4.84\%. In other words the contribution of cloud-oriented tools of supporting joint research and study activities in the formation of the major research competencies, according to experts, is negligible. Nevertheless the indicators of the contribution to GRC-10 formation are the possible maximum that can be practically achieved. It proves the enormous role of these tools in the formation of the above-mentioned competences.

This research has used cloud services appropriate for organizing joint education activities presented in the way of relevant documents (text files, presentations, etc.) with an open access for sharing and editing while organizing pupils' individual work, project group work, consulting teacher work, etc.

The specific cloud-oriented tools of supporting collaborative study activities are ICTs for project management. This kind of software that is 
typically focused on business project management such as: event planning and task management through the procedure of identifying and decomposing project components, building a hierarchical work structure, planning of interconnected events, resource allocation for specific tasks, tasks distribution among different executors, the calculation of time required for project, constructing the schedule of task implementing and Gantt charts, task sorting, simultaneous managing of several projects. In addition, project management tools provide the ability to manage data (creating task lists, collecting data on the timing of work, warning of potential risks, workload data, project progress, indicators and their prediction), project management communications (discussing project working issues, fixing problems and requests for changes, taking into account project risks, providing access to project progress data). The above mentioned options can also be effective in profile Chemistry learning for the organizing cooperative study research work, primarily remote one.

Adaptive automated Chemistry training systems, despite the significant contribution to the general development of research competencies system among senior pupils in profile Chemistry learning, which is $12.57 \%$, are an important tool of forming only one competence - CRC-09. It should be noted that this ICT tool has a great impact on the formation of other chemical expertise, in particular, CRC-01, CRC-06, CRC-07 and CRC-12.

Virtual chemical laboratories (VCL) are a leading tool in simultaneous forming of ten research competencies. For all of them, VCL have been recognized by experts as the only leading ICT tools. Among of these research competencies are SRC-02, SRC-04, SRC-05, CRC-03, CRC-04 and CRC-12.

The formation of four other research competencies requires the usage of not only VCL as the leading one, but also some other ICTs: SRC-03, CRC-02, CRC-05 and CRC-07. In general, the contribution of VCL to the formation of research competencies system among senior pupils in the profile Chemistry learning is the largest of all ICT tools, and it is $24.84 \%$. Thus, VCL can be considered as the most influential and most universal ICT tools for research competencies formation among senior pupils in the profile Chemistry learning.

Studying of the elective course "Basics of Quantitative Chemical Analysis" gives VCL the variety of important roles: training before conducting field experiments and laboratory works (including the individual work and homework); modeling of processes and phenomena that make up the theoretical method basis of Quantitative Chemical Analysis, in order to find out their essence and determine their peculiarities; conducting virtual 
laboratory works and experiments, which obviously can not be carried out as a full-scale experiment; implementing a laboratory workshop in the form of distance learning for individual student study.

For this purpose, the complementary sets of laboratory works are created in two VCLs (Virtual Lab and ChemLab [10]). Also relevant software products in Ukrainian are localized, and a VlabEmbed plugin is created to build in the Virtual Lab into the pages of the site on the Moodle platform [6]. Taking into account the various possibilities of the Virtual Lab and the ChemLab for simulating different processes, created virtual laboratory kits are not interchangeable but complementary, giving the opportunity to increase the formation of the relevant research competencies among senior pupils in terms of performing the virtual laboratory work.

Electronic periodic systems are the leading tools for the formation of GRC-05, CRC-06 and CRC-08. The total contribution of electronic periodic systems in forming research competencies system among senior pupils in the profile Chemistry learning is $7.55 \%$.

Electronic periodic systems are used in the process of profile Chemistry leaning as a source of reference data and a convenient means of its ordering. It is also a tool for expanding the chemical horizons, mastering the modern chemical nomenclature etc. Directly supporting the elective course "Basics of Quantitative Chemical Analysis", electronic periodic systems are used as a source of reference data. However, when revising the topic "Periodic law and periodic system of chemical elements", as well as leaning Elemental Chemistry in the 10th grade, this ICT tool is an extremely convenient one for work both during lessons, and for the organizing individual, study and research work among senior pupils.

The tools for computer modeling of chemical processes due to the methods of Molecular Mechanics and Dynamics, Quantum Chemistry, etc., are hardly used in the practice of profile Chemistry learning. They are to solve rather complex and specific chemical problems related to theoretical calculations and modeling of molecular structures, intermolecular interactions, the influence of conditions on the course of physical and physical-chemical processes, etc. Their applying is considered to be used for the study and research activity of pupils in the fields of Organic, Bioorganic and General Chemistry at a high theoretical level. The total contribution of the computer simulation of chemical processes to the formation of research competencies system among senior pupils in the profile Chemistry learning is $11.16 \%$.

Despite the relative complexity of their use, these ICTs have been identified as the leading tools by the expert evaluation of the SRC-08, 
CRC-07, CRC-08, CRC-10, and CRC-11 formation. For two latter ones the tools for computer modeling of chemical processes are the only ones.

Chemistry educational games is the leading ICT tool in forming GRC06, but the overall contribution of Chemistry training games to forming research competencies system among senior pupils in the profile Chemistry learning is quite significant and it is $8.07 \%$.

This expert opinion correlates with the views of S. O. Terno, who believes that critical thinking is primarily aimed at solving a certain problem (difficulty) [16, p.44], and its source may be a game. Games provide an inviting opportunity for learners to discover and develop skills and knowledge that can be used later in real life. Moreover it helps to test different solutions for problem situations and to get an idea of action effectiveness, which improves their situational assessment and critical thinking skills [1].

David E. Henderson [3] offers the pattern of a Business Chemistry game aimed to develop pupil critical thinking in the process of information searching. This game can use both conventional data sources (often scientific libraries), accessible through the general-purpose search systems, as well as specialized ones, accessible through the popular science and vocational chemical information Internet resources, chemical search systems, etc. The plot of the game is to identify, study and verify the need to develop and produce new chemical equipment for chemical analysis (spectrometric, electrochemical, voltammetric, magnetic resonance, radiographic, etc.). During the game ICTs are used, such as electronic spreadsheets (for data analysis), mindmaps (for displaying different proposals to select the best one), tools for providing instructional communication in asynchronous and synchronous modes (for group learning and research activities), tools for planning educational activities and cloud-oriented supporting tools for joint study and research activities (for planning and monitoring the stages of project implementation), the web-conferencing learning tools (for remote meetings and discussions), word processing tools and multimedia presentation creators (for a visual representation of progressing, intermediate and final study results).

For example, the subject of the Chembridge Chemistry game requires the players to have the define the oxidation state of chemical elements in compounds, and to make reasonable assumptions about the redox properties of these compounds. It also contributes to the development of critical thinking, since every game situation requires a well-balanced action approach. For instance, one of the cards denotes the $\mathrm{TiF}_{3}$ substance. It is difficult to put the oxidation state at once (in the Fluoro atom, the 
oxidation state is -1 , and in the Titan atom +3 , respectively). But what properties will this compound obtain in chemical reactions with other substances: only oxidation, only reduction, or oxidation and reduction depending on the reaction? The course of measurements should be as follows: Titan's atom is in the intermediate oxidation state, and therefore it can be an oxidizer and a reducer, while the Fluoro atom is at its lowest oxidation state, therefore, it can only be a reducer. However, such strong oxidizers do not exist to interact with the Fluoro atom in the oxidation state -1 . That is why no attention should be paid to the properties of Fluoro in this (or similar) compounds. Consequently, $\mathrm{TiF}_{3}$ will have both oxidizing and reducing properties, depending on the chemical reaction, due to the intermediate oxidation state of the Titan atom in this compound.

It should be mentioned that the significant number of tasks in the VCL Virtual Lab is made up in the way of the game. To some extent it erases the boundary between games and VCL.

Popular science and vocational Chemistry information Internet resources are the leading ICT tools of GRC-05, GRC-06, GRC-04, SRC-01, SRC-07 formation. As for the three latter of the listed research competencies, the popular science and vocational Chemistry information Internet resources are considered the only ICT leading tool. The total contribution to the formation of research competencies system among senior pupils in the profile Chemistry learning is $12.89 \%$.

Unlike Chemistry textbooks that have to concentrate the pupil's attention on the certain set of facts, definitions, patterns and rules, written mostly, in a rather "dry" scientific language, science popular Chemistry Internet resources usually do not have these restrictions. They pay more attention to the description of vivid or unusual facts associated with a chemical object; the history of scientific research; the practical usage of chemicals, reactions, laws; the interconnection of Chemistry with other sciences. The way of data submission in the popular science and vocational Chemistry information Internet resources is also varied in style (maybe both scientific and journalistic, as well as artistic or even colloquial), and in mode (in addition to the text and photos, there can be used animation, video material, feedback from the author or other users, etc.).

The above-mentioned content features of the science popular and vocational Chemistry Internet resources make them, according to experts, the only one effective tool of GRC-04, SRC-01 and SRC-07 development. For example, the on-line version of the journal "Chemistry and Life" (https://www.hij.ru/) provides an opportunity to read articles published in the journal. These papers encourage readers to think over ethical, moral, 
social and the economic problems of researching in Chemistry and other Natural Sciences and form the attitude towards them. They contain a detailed description of discoveries history in the field of Chemistry or methods of chemical research. Moreover they uncover the problems of other Natural Sciences and their interrelation with Chemistry.

The same content has the Internet magazine "Chemistry and Chemists" (http://chemistry-chemists.com/) and other similar resources.

Chemical information Internet resources often contain a large number of reference materials. In particular, on the Chemiday.com site, there is an electronic periodic system, a table of salts acids and bases water solubility, a chemical reaction database, a chemical encyclopedia, the register of edible additives, etc. However it does not claim to be full and complete as this resource constantly improves. That is why if the necessary data is not found, it can searched on other similar resources (xumuk.ru, chemport.ru, etc.).

Taking into consideration the sufficient amount of such resources on Internet, their availability, constant expansion and improvement, it is logical to assume that the most important contribution of popular science and vocational Chemistry Internet resources as ICT tools in forming components of research competencies system among senior pupils in the profile Chemistry learning falls is related to GRC- 05 formation.

Critical thinking is based on the cognitive skills of analysis, interpretation, conclusion making, explanation, evaluation, monitoring and correcting of individual thinking. Therefore, critical thinking to a certain extent reproduces the process of scientific research as it identifies the problem. It also states the hypothesis, collects and analyzes relevant data, tests and eventually accepts or rejects the hypothesis, and finally makes conclusions [2].

The popular science and vocational Chemistry Internet resources allow going beyond the school curriculum, to obtain data on chemical objects through different perspectives and sources, following the research thinking or the sequence of experiments, which provide the opportunity to develop GRC-06.

For example, while studying the topic "Alkaline elements" (10th grade), pupils are recommended to read the series of articles in the journal "Chemistry and Chemists" (http://chemistry-chemists.com/Video/NaH2O.html), devoted to the properties of metallic sodium and its experiments. In addition to the detailed description of the experiments, their photos and videos, the articles also contain additional facts which, usually are not described into the textbooks, due to their exceptional 
status. They often require detailed and rather complicated explanations. In particular, one of the articles describes the sodium reaction with concentrated hydrochloric acid, which proceeds surprisingly much less violent than the same reaction with water. The paper explains these results due to the formation of sodium chloride insoluble in chloride acid on the metal surface of a protective film that protects sodium from further interaction with $\mathrm{HCl}$. The discussion of such rule exceptions encourages pupils to examine comprehensively the problem situation, taking into account all factors and thoroughly checking the hypothesis that is at first obviously correct, and, if necessary, reasonable correcting of this hypothesis and making final conclusions.

Chemistry program and method complexes used in studying are multicomponent software tools specially created and intended directly to support the study of certain topics or sections of the school Chemistry course. That is why their overall contribution to the formation of research competencies system among senior pupils in Chemistry is high. It is about $23.54 \%$, and comparatively inferior less only than the contribution value of VCL. Chemistry program and method complexes have been identified by experts as the only leading tool for the $\mathrm{CRC}-01$ formation, as well as the leading tools for the formation of SRC-03, CRC 05, CRC-06 and CRC-09.

As a rule, the usage sphere of above-mentioned program and method complex is marked in its tittle. Its functional capabilities provide the opportunity to use it as an electronic tutorial, as well as the tools of checking the level of knowledge or a simulator etc.

The total contribution of simulators and electronic workshops to the formation of research competencies system among senior pupils in the profile Chemistry learning is significant and amounts to $15.72 \%$, but these tools are considered to be the leading ones for the formation of CRC-02 and CRC-09. Also, these tools affect considerably the formation of such research competencies as CRC-01, CRC-04 and CRC-05.

In general, simulators and electronic workshops in their functional capabilities and appointments are similar to VCL, but their options are much more limited, since their functioning is based on the implementation of only one algorithm aimed at working out the correct order of actions and observations. Therefore, these tools influence the formation of practically the same research competencies as the VCL, but this list is smaller and the impact of simulators and electronic workshops on the process of forming the above-mentioned research competencies is not so significant.

Chemistry search systems, as well as general-purpose search systems are the leading ICT tools for GRC-05 only, and their overall contribution 
to the development of research competencies system among senior pupils is less than that of general-purpose search systems. It is only $5.25 \%$.

Chemistry search systems are powerful Chemistry databases with not only specific keyword search (names of substances or fragment names). They also contain special codes (linear notes) that reflect the structure of molecules and using two-dimensional structure formuli of substances or their fragments (structure search and similarity search).

Chemistry search systems can differ significantly in their database content that provides their specialization. Some search systems contain important information about the chemical and physical properties of substances, the others include facts about manufacturers and prices for chemical products, the third describe the biological activity of molecules etc.

The use of Chemistry search systems in the profile Chemistry learning allows obtaining reference data, necessary for problem solving, the links of literature references, the review of physical and chemical properties, and synthesis methods, skills to work with a specific tool for chemical data search etc.

A certain disadvantage of Chemistry search systems can be defined as follows: almost all of them are monolingual and the ability to search or browse data in other languages is not supported.

Chemical editors are specific software products, and their prime value is the visualization of chemical symbols. That is why these tools are the guiding ones in the formation of CRC-06. The influence of chemical editors on the formation of other research competencies is insignificant. As evidenced by the magnitude of their overall contribution to the formation of research competencies system among senior pupils in the profile Chemistry learning it is $3,36 \%$.

Chemical editors are used predominantly at the stage of introducing the research results. As a rule, text editors provide the ability to present the majority of chemical language peculiarities (chemical formuli, reaction equations, simple conversion schemes, etc.). However the chemical editors become the only effective tool, when it is necessary to create more complex and specific graphic objects such as: structural formuli of substances, transformation schemes of chemical compounds, images of chemical utensils and appliances, etc. While using a chemical editor, pupils not only get skills of working with such an important ICT tool for a future chemist, but also improve their own knowledge of the chemical nomenclature, the structure of substance, chemical dishes, etc. 


\section{Conclusions}

1. According to the results of the expert assessing the expediency of using ICT tools for the formation of individual research competencies the following conclusions are made: among 17 selected ICTs, the formation of research competencies of 7 tools is specific (they are leading in the formation of only one research competence). 9 tools are multifunctional, as they are leading in the formation of two and more research competencies. Finally 1 tool is not conducive to the formation of any research competence. The most significant and effective ICT tools for the formation of the whole system of research competencies among senior pupils in the profile Chemistry learning are virtual chemical laboratories and Chemistry program and method complexes. Their relative contribution to the formation of the research competencies system is $13.87 \%$ and $13.14 \%$ respectively. The other tools show contributions from $5 \%$ to $10 \%$. In particular, such facilities as simulators and electronic workshops receive $8.78 \%$; popular science and vocational chemical information Internet resources get $7.20 \%$; tools for creating multimedia presentations take $7.12 \%$; adaptive automated Chemistry training systems in are at $7.02 \%$; tools for computer modeling of chemical processes reach $6.23 \%$ and general-purpose search systems have $5.24 \%$. Chemistry educational games show the lowest contribution to the development of research competencies system among senior pupils (4,51\%). The following results represent the other tools: learning management systems $(4,28 \%)$; electronic periodic systems $(4,21 \%)$; text editors $(4,05 \%)$; electronic spreadsheets (3.71\%); tools of educational achievements control and self-control (3.14\%); Chemistry search systems $(2.93 \%)$; cloud-oriented tools of supporting joint research and study activities $(2.70 \%)$ and chemical editors $(1.88 \%)$. Despite the relatively low level of knowledge for developing the system of research competencies, these tools can not be excluded from a list of ICTs, as they are promising tools for the formation of at least one of the research competencies.

2. Proceeding from the fact that the formation of research competencies system among senior pupils is effective due to the correct selection of ICT tools and the conditions of their applying for the formation of each of the research competencies system components. Based on the results of research and experimental work it has become possible to develop recommendations for using ICT tools in the process of 
forming the research competencies among senior pupils while their profile Chemistry learning. The majority of leading ICTs has been tested through their use in the process of studying the electives course "Basics of Quantitative Chemical Analysis". The possibility of applying some ICTs for the formation of research competencies is demonstrated by certain topics of the school Chemistry course in profile senior school.

\section{References}

1. Blanchard, E. G., Frasson, C., Lajoie, S. P.: Learning with Games. In: Seel, N. M. (ed.) Encyclopedia of the Sciences of Learning, pp. 20192024. Springer, New York (2012).

2. Gokhale, A. A.: Collaborative Learning and Critical Thinking In: Seel, N. M. (ed.) Encyclopedia of the Sciences of Learning, pp. 634-636. Springer, New York (2012).

3. Henderson, D.E.: A Chemical Instrumentation Game for Teaching Critical Thinking and Information Literacy in Instrumental Analysis Courses. Journal of Chemical Education. 87 (4), 412-415 (2010).

4. Nechypurenko, P. P., Semerikov, S. O., Selivanova, T. V, Shenayeva, T. O.: Information and communication tools for pupils' research competence formation at chemistry profile learning. Information Technologies and Learning Tools. 56 (6), 10-29 (2016).

5. Nechypurenko, P.P., Semerikov, S. O., Tomilina, L. I.: Teoretykometodychni zasady vykorystannia informatsiino-komunikatsiinykh tekhnolohii yak zasobu formuvannia doslidnytskykh kompetentnostei starshoklasnykiv u profilnomu navchanni khimii (Theoretical and methodical foundations of using ICT as a tools of forming the senior pupils' research competencies in the chemistry profile learning). Publishing Department of the SIHE "Kryvyi Rih National University", Kryvyi Rih (2018).

6. Nechypurenko, P. P., Semerikov, S. O.: VlabEmbed - the New Plugin Moodle for the Chemistry Education. In: Ermolayev, V., Bassiliades, N., Fill, H.-G., Yakovyna, V., Mayr, H. C., Kharchenko, V., Peschanenko, V., Shyshkina, M., Nikitchenko, M., Spivakovsky, A. (eds.) ICT in Education, Research and Industrial Applications. Integration, Harmonization and Knowledge Transfer 2017, 13th International Conference on ICT in Education, Research and Industrial Applications. Integration, Harmonization and Knowledge Transfer (ICTERI, 2017), 
Kyiv, Ukraine, 15-18 May 2017. CEUR Workshop Proceedings (CEURWS.org), vol. 1844, pp. 319-326 (2017).

7. Nechypurenko, P.P.: Deiaki aspekty imitatsii realnykh khimichnykh protsesiv ta system u virtualnykh khimichnykh laboratoriiakh (Some aspects of simulation of real chemical processes and systems in virtual chemical laboratories). Theory and methods of e-learning. 3, 238-244 (2012).

8. Nechypurenko, P. P.: Dobir ta ekspertyza zasobiv IKT dlia formuvannia doslidnytskykh kompetentnostei uchniv u profilnomu navchanni khimii (Selection and examination of ICT tools for pupils' research competencies in the chemistry profile learning). In: Proceedings of the Fourth IV All-Ukrainian Scientific and Practical Conference of Young Scientists "Scientific Youth-2016", IITLT, Kyiv, 15 Dec 2016.

9. Nechypurenko, P.P.: MarvinJS yak zasib pidtrymky navchalnodoslidnytskoi diialnosti uchniv $\mathrm{z}$ khimii (MarvinJS as a tool of support of pupils' learning and research activity of chemistry). In: Proceedings of the Fourth International Scientific and Practical Conference "MoodleMoot Ukraine 2016. Theory and Practice of Using the Moodle Learning Management System", KNUBA, Kyiv, 19-20 May 2016.

10. Nechypurenko, P.P.: Pro vykorystannia kompiuternoi prohramy Chemlab (About the use of the computer program Chemlab). Biology and chemistry at school. 2, 44-47 (2007).

11. Nechypurenko, P. P.: Systema doslidnytskykh kompetentnostei uchniv starshoi shkoly u profilnomu navchanni khimii (The system of research competencies of high school students at chemistry profile learning). Bulletin of Cherkasy University. Series: Pedagogical Sciences. 7, 83-90 (2016).

12. Nechypurenko, P.P.: Systema Moodle yak zasib formuvannia doslidnytskykh kompetentnostei uchniv u profilnomu navchanni khimii (The system Moodle as a tool of formation of pupils' research competencies in the profile chemistry learning). In: Proceedings of the Third International Scientific and Practical Conference "MoodleMoot Ukraine 2015. Theory and Practice of Using the Moodle Learning Management System", KNUBA, Kyiv, 21-22 May 2015.

13. Nechypurenko, P.P.: Teaching and research activities of students in chemistry profile school as a means of formation of research competencies. New computer technologies. 14, 135-136 (2016). 
14. Nechypurenko, P.P.: Virtualni khimichni laboratorii $\mathrm{v}$ protsesi navchannia khimii: suchasnyi stan ta perspektyvy (Virtual chemical laboratories in the teaching chemistry process: current state and prospects). Scientific journal of the National Pedagogical University named after M. P. Dragomanov. Series number 5. Pedagogical sciences: realities and perspectives. 33, 95-102 (2012).

15. Nechypurenko, P. P.: Vyvchennia osnov khimichnoho analizu zasobamy kompiuternykh tekhnolohii ta yoho mistse $\mathrm{v}$ ekolohichnii osviti shkoliariv (Study of the basics of chemical analysis by computer technology tools and its place in the ecological education of schoolchildren). In: Proceedings of the VII International scientific and practical conference on Problems of ecology and ecological education, Kryvyi Rih (2008)

16. Terno, S. O.: Teoriia rozvytku krytychnoho myslennia (na prykladi navchannia istorii) (The theory of the development of critical thinking (by example the history learning)). Zaporizhzhya National University, Zaporizhzhya (2011). 